\title{
Molecular Study of NPM1-A (Nucleophosmin1-A) Mutation in Iraqi Adult Acute Myeloid Leukemia Patients; Its Correlation with Clinicopathological Parameters
}

\author{
Shaymaa Abdulateef ${ }^{1, ~}$, Ali Almothaffar ${ }^{2}$, Khitam Razzak Al-khafaji ${ }^{3}$ \\ ${ }^{1}$ Baquba Teaching Hospital, Diyala, Iraq \\ ${ }^{2}$ Department of Medicine, University of Baghdad, Baghdad, Iraq \\ ${ }^{3}$ Department of Pathology and Forensic Medicine, University of Baghdad, Baghdad, Iraq
}

Email address:

sh2010ine@gmail.com (Sh. Abdulateef)

${ }^{*}$ Corresponding author

\section{To cite this article:}

Shaymaa Abdulateef, Ali Almothaffar, Khitam Razzak Al-khafaji. Molecular Study of NPM1-A (Nucleophosmin1-A) Mutation in Iraqi Adult Acute Myeloid Leukemia Patients; Its Correlation with Clinicopathological Parameters. American Journal of Internal Medicine. Vol. 5, No. 3, 2017, pp. 37-40. doi: 10.11648/j.ajim.20170503.11

Received: March 3, 2017; Accepted: March 20, 2017; Published: April 19, 2017

\begin{abstract}
Acute myeloid leukemia (AML) is a hematological malignancy of myeloid progenitor cells characterized by anomalous proliferation, inhibition of differentiation and expansion of leukemic cells blocked at the early stage of hematopoiesis. The molecular markers have become a smart tool to further division of AML patients into subgroups. Nucleophosmin (NPM1) mutations are found in approximately $30 \%$ of adult AML patients and are associated with a favorable outcome when detected in absence of FLT3-ITD mutation. Over 50 molecular NPM1 mutation variants have been identified; the most common one is NPM1-A mutation. The current study aims to detect; the frequency of NPM1-A in Iraqi adult newly diagnosed AML patients using real time - PCR technique and evaluate the relationship of NPM1-A with age, gender, total white blood cell (WBC) count and FAB subtypes of the disease. The frequency of NPM1-A mutation in newly diagnosed AML patients was $18.86 \%$. Age was non-significantly higher in NPM1-A mutated patients than in patients without mutation $(\mathrm{P}=0.538)$. The NPM1-A mutation was predominantly seen in male $(\mathrm{P}=0.069)$. The mutation was non-significantly higher among monocytic subtypes (M5+M4) compared with the other subtypes of the disease ( $\mathrm{P}=0.916)$. In the NPM1 mutated group, the total WBC count was non-significantly higher than the non-mutated group $(\mathrm{P}=0.302)$. These findings suggest; Real timePCR technique using TaqMan probe was very specific molecular test for this mutation. Mutated NPM1-A patients were associated with increased age, a higher total WBC count, male predominance and the monocytic subtypes of the disease.
\end{abstract}

Keywords: Acute Myeloid Leukemia, NPM1-A, Real Time-PCR

\section{Introduction}

Acute myeloid leukemia (AML) is characterized by a clonal proliferation of myeloid precursors with a reduced capacity to differentiate into more mature cellular elements. As a result, there is an accumulation of leukemic blast cells or immature forms in the bone marrow, peripheral blood, and infrequently in other tissues, with a variable lowering in the production of normal red blood cells, platelets, and mature granulocytes. [1] Generally AML is a disease of later adulthood; the average age of newly diagnosed patients is 65 -
70 years. [2]

Advances in molecular research have greatly improved understanding of the leukemogenesis in AML. [3] In addition to the conventional risk factors, such as age, white blood cell (WBC) counts and cytogenetics, molecular genetic alterations, such as mutations of NPM1, FLT3, CEBPA, AML1/RUNX1, WT1, TET2, and DNMT3A are also important prognostic factors in acute myeloid leukemia patients. [3]

Nucleophosmin (NPM1) is a nuclear and cytoplasmic protein, which functions as a molecular chaperone to prevent protein aggregation in the nucleolus and to regulate p53 
levels. [4] Point mutations within the C-terminal region of the NPM1gene result in cytoplasmic accumulation of the mutated NPM protein. [4, 5] The most frequent form of Mutation is duplication of TCTG (type A, 860-863 dupTCTG). [5]

AML with mutated NPM1 has been included in the 2008 World Health Organization (WHO) classification of myeloid neoplasms as a provisional entity. [6] NPM1 mutation occurs in about $30 \%$ of AML, more frequently in elder patients, and is highly associated with normal karyotype, and FLT3/ITD, favorable karyotype, and expression of CD34 and HLA-DR $[7,8,9]$

\section{Patients, Materials and Methods}

This is a cross-sectional study, from $1^{\text {st }}$ of April 2015 through September 2016. The bone marrow aspirate (BMA) samples of 53 adult AML patients were collected at the time of diagnosis and prior to treatment at the Hematology Ward of Baghdad Teaching Hospital in Medical City compared with 53 control individuals (age and sex matched). All the control bone marrows were negative for infiltrative lesions and obtained from patients with anemia and idiopathic thrombocytopenic purpura. The related clinical and laboratory data for each patient were registered at the time of diagnosis. AML patients were diagnosed according to the FAB criteria. [10] Immunophenotyping was done where it was deemed necessary, in patients with diagnostic uncertainty.

From each patient, $0.5 \mathrm{ml}$ of BMA was taken and equally distributed into 2 tubes; each contain $(1.5 \mathrm{ml})$ erythrocyte lysis buffer mixed well and incubated for 15 minutes then centrifuged at $1800 \mathrm{rpm}$ for $10 \mathrm{~min}$ at $4^{\circ} \mathrm{C}$. The supernatant was removed and discarded. New erythrocyte lysis buffer $(500 \mu \mathrm{l})$ was added to the cell pellet. The tubes centrifuged at $1800 \mathrm{rpm}$ for $10 \mathrm{~min}$ at $4^{\circ} \mathrm{C}$, supernatant was removed and discarded. Buffer RLT $(600 \mu \mathrm{l})$ was added to pelleted leukocytes. The samples were frozen and stored at $-40^{\circ} \mathrm{C}$ until the day of RNA extraction.

QIAamp ${ }^{\circledR}$ RNA Blood Mini kit (Qiagen, Germany) was used to extract RNA and then the RNA was reverse transcribed into cDNA using QuantiTect ${ }^{\circledR}$ Reverse Transcription kit (QIAGEN, Germany) $\left(42^{\circ} \mathrm{C}\right.$ for 30 minutes, followed $95^{\circ} \mathrm{C}$ for 3 minutes). The final volume for PCR reaction was $20 \mu \mathrm{L}$ containing $100 \mathrm{ng}$ cDNA, $10 \mu \mathrm{L}$ of TaqMan ${ }^{\circledR}$ Universal Master Mix II, with UNG (Applied Biosystems, USA), $300 \mathrm{nmol} / \mathrm{L}$ of forward primerand 600 for reverse primers, using the primers:NPM1-A- Reverse, (5'CTT CCT CCA CTG CCA GAC AGA-3') NPM1-AForward, (5'TCGTGTGTGAAACTCCAGACT3'), and 150 nmolNPM1-A-TaqMan Probes labeled with FAM and MGB3'dyes (5'-FAM-ACC AAG AGG CTA TTC AAG AT-MGB$\left.3^{\prime}\right)$. ABL housekeeping gene labeled with VIC and MGB-3 dyes used as internal control for NPM1-A, using the primers: ABL- Reverse (5'-GATGTAGTTGCTTGGGACCCA-3') ABL- Forward (5'TGGAGATAACACTCTAAGCATAACTAAAGGT-3') and ABL- Probe (5'-VICCCATTTTTGGTTTGGGCTTCACACCATT-MGB-3'). All the primers were designed using Primer Express Software (Applied Biosystem, Foster City, CA, USA). Real-time polymerase chain reaction (PCR) assays using Mx3000PTM real time PCR System sequence DetectionSystem (Stratagene, USA) was done by heating at $50^{\circ} \mathrm{C}$ for 2 minutes, $95^{\circ} \mathrm{C}$ for 10 minutes, followed by 40 cycles of $95^{\circ} \mathrm{C}$ for 15 seconds, $60^{\circ} \mathrm{C}$ for 1 minute. Real-time polymerase chain reaction (PCR) assays usingMx3000PTM sequence Detection System (Stratagene, USA) data were analyzed using Real-time polymerase chain reaction (PCR) assays using Mx3000PTMsequence Detection.

The NPM1-A mutated cases showed amplification of target sequence NPM1-A (figure 1); while patients negative for NPM1-A mutation and control cases showed no amplification product. All AML and control cases showed amplification of ABL transcript.

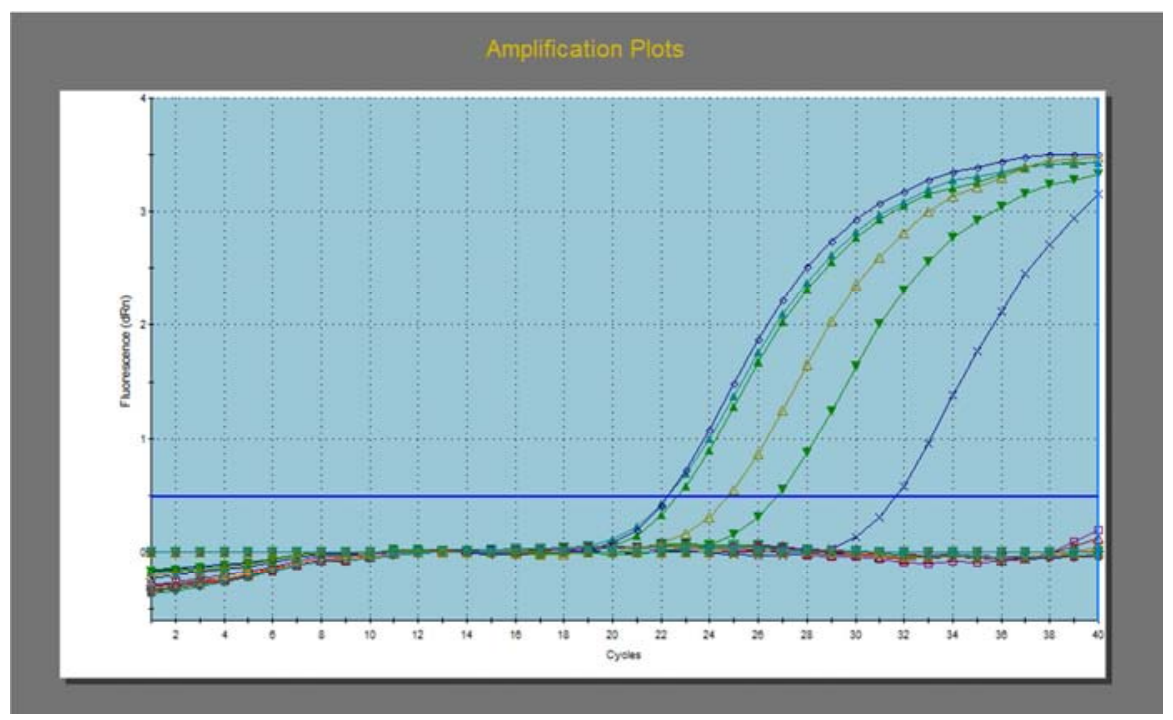

Figure 1 Real time PCR amplification plots for NPM1-A cDNA in AML patients using TaqMan probe (FAM), where amplification curves are AML samples positive for NPM-A mutation. 


\section{Statistical Analysis}

Data were analyzed using statistical software program SPSS version 22 (SPSS Inc. Chicago, IL, USA). Continuous data were expressed as mean \pm standard deviation (SD); frequency was used to express categorical data. Student t-test was used to analyze continuous data while Chi-square was used to analyze categorical data. Values were considered statically significant when $\mathrm{P}$ value $(<0.05)$.

\section{Results}

Table 1. Association of age and WBC count with NPM1-A mutation in AML patients.

\begin{tabular}{llll}
\hline & \multicolumn{2}{c}{ NPM1-A mutation } & $\begin{array}{l}\text { P } \\
\text { value }\end{array}$ \\
\cline { 2 - 3 } & Positive (10 cases) & Negative (43 cases) & 0.538 \\
\cline { 1 - 1 } $\begin{array}{l}\text { Mean Age }( \pm \mathrm{SD}) \\
\text { years }\end{array}$ & $47.60( \pm 22.83)$ & $43.42( \pm 18.31)$ & 0.302 \\
$\begin{array}{l}\text { Total WBC count } \\
( \pm \mathrm{SD}) \times 10^{9}\end{array}$ & $50.37( \pm 56.05)$ & $30.46( \pm 51.09)$ & \\
\hline
\end{tabular}

Table 2. NPM1-A mutation in AML patients according to gender.

\begin{tabular}{llll}
\hline \multirow{2}{*}{ NPM1- A mutation } & \multicolumn{2}{l}{ Gender } & \multirow{2}{*}{ Total } \\
\cline { 2 - 3 } & Male & Female & \\
\hline Positive & 9 & 1 & $10(18.86 \%)$ \\
Negative & 23 & 20 & $43(81.13 \%)$ \\
Total & 32 & 21 & $53(100 \%)$ \\
$\mathrm{P}=0.069$ & & & \\
\hline
\end{tabular}

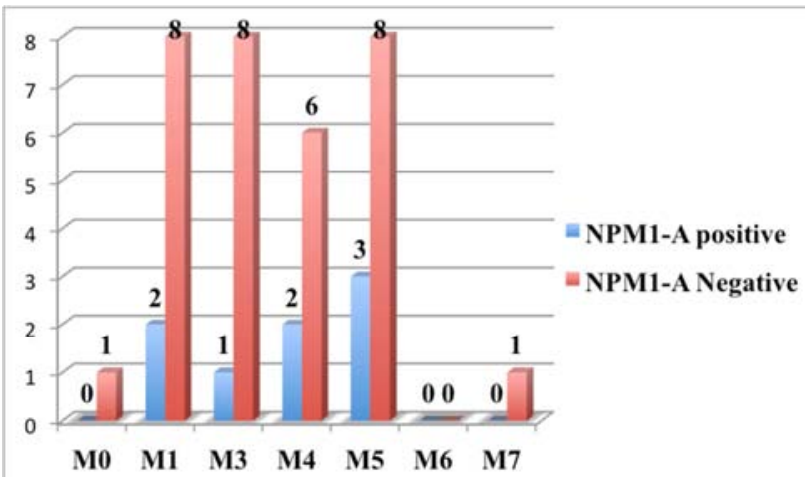

Figure 2. NPM1-A mutation according to FAB classification of $A M L$ patients.

The study was focused on 53 newly diagnosed Iraqi AML patients (Age range 15-83 years; median 42.00). The NPM1A mutation was identified in $10(18.86 \%)$ of the $53 \mathrm{AML}$ patients. The mean age of patients with NPM1-A mutation was non-significantly higher than patients without mutation $(47.60 \pm 22.83 ; 43.42 \pm 18.31$ years, respectively) $(\mathrm{P}=0.538)$ as shown in table (1). The NPM1-A mutation was predominantly seen in male ( 9 out of 32 males and 1 out of 21 females), however; this was statistically not significant $(\mathrm{P}=0.069)$ as shown in table (2). The NPM1-A mutation was more frequent in the patients classified as M5 (3/11) and M4 $(2 / 8)$ followed by M1, M2 and M3 in (2/10), (2/13), (1/9) patients respectively while NPM1-A mutation was not detected in patients with the M0 (0/1) and M7 (0/1) subtypes
(Figure 2). The mutation was non-significantly higher among monocytic subtypes (M5+M4) compared with the other subtypes $(\mathrm{P}=0.916)$. In the NPM1 mutated group, the WBC count was non-significantly higher $(\mathrm{P}=0.302)$ than the nonmutated group $(50.37 \pm 56.05 ; 30.46 \pm 51.09$, respectively) $(\mathrm{P}=0.302)$.

\section{Discussion}

In this study; among all adult newly diagnosed AML patients, $18.86 \%$ had NPM1-A mutation. This result was extremely lower than previously reported by earlier studies in Iraq, [11, 12, 13] in which the NPM1 mutations were detected in $56.66 \%, 46.88 \%, 34.37 \%$ of AML patients; respectively. [11, 12, 13] The lower detection rate in this study may be due to variable number of cases, and different methods had been used to screen and assess NPM1 mutations. These include use of immunohistochemistry, [11] SSCP-RT-PCR, [12] and ASO-RT-PCR. [13] In the current study, QRT-PCR technique using TaqMan assay was used to screen AML patients with NPM1-A mutation.

This study was similar to that reported by Pazhakh et al from Iran who revealed NPM1 mutation in $17.5 \%$ of their patient's series. [14]

This result was in contrast to many western studies, which implied a higher frequency of NPM1 mutations in AML patients with normal karyotype. The low frequency of NPM1-A mutation in the present study in relation to other studies might be explained by the fact that, most researchers had focused on NPM1 mutations in normal karyotype AML in general whereas; in the current study assessment of the frequency of NPM1-A mutation among AML cases with normal karyotype was not possible.

The mean age of adult patients with NPM1-A mutation was non-significantly higher than that of non-mutated patients $(\mathrm{P}=0.507)$. Rau and Brown emphasized high frequency of NPM1 mutations in middle-aged adults or more elderly individuals. [15]

The rate of NPM1-A mutation in males was higher than in females with $\mathrm{M}$ : F ratio 9:1 $(\mathrm{P}=0.069)$. Which was differing from that had been stated by several clinical studies. [12, 16, 17, 18] Population genetics, environmental factors, smaller sample number of enrolled patients and mean age of female was lower than that of males (38.95 vs 47.65 years), or a combination of all might account for the lower frequency of NPM1-A mutation in females.

Although, the means of WBC count of mutated AML patients in current study were higher than non-mutated patients, these correlations were not significant. Many workers had emphasized a higher WBC count, [19, 20, 21, 22] in NPM1 mutated patients as compared to non-mutated patients. Chen et al [23] and Dohner et al [47] stated that mutant NPM1 genes tend to have higher WBC count than AML patients carrying wild type NPM1 gene. [21, 23]

The frequency of NPM mutation among FAB subgroups was heterogenous being higher among monocytic subtypes 
(M5+M4) $(\mathrm{P}=0.916)$, this finding corroborated by other studies; which found that NPM mutation was frequent among FAB groups with monocytic differentiation. [20, 21, 25, 26]

\section{Conclusion}

Real time PCR technique is very specific test for detection of molecular markers including NPM1-A mutation. AML patients with NPM1-A mutation are positively associated with increased age, a higher WBC count, male predominance and the monocytic subtypes of the disease

\section{References}

[1] Charles A Schiffer, John Anastasi. Clinical manifestations, pathologic features, and diagnosis of acute myeloid leukemia. Up To Date: Jan 21, 2015.

[2] Visser O, Trama A, Maynadie M, Stiller C, Marcos-Gragera R, De Angelis R, Mallone S, Tereanu C, Allemani C, Ricardi $\mathrm{U}$, Schouten HC. Incidence, survival and prevalence of myeloid malignancies in Europe. European Journal of Cancer. 2012 Nov 30; 48 (17):3257-66.

[3] Hou HA, Tien HF, Chou WC. Genetic Alterations and Their Clinical Implications in Acute Myeloid Leukemia. INTECH Open Access Publisher; 2011.

[4] Thiede C, et al. Different types of NPM1 mutations in children and adults: evidence for an effect of patient age on the prevalence of the TCTG-tandem duplication in NPM1exon12. Leukemia (2007) 21:366-7.

[5] Braoudaki M, et al. The frequency of NPM1 mutations in child- hood acute myeloid leukemia. J HematolOncol (2010) $3: 41$.

[6] Arber D. A, et al. Acute myeloid leukemia (AML) and related precursor neoplasms. In: Swerdlow S. H, et al, eds. WHO Classification of Tumors of Haematopoietic and Lymphoid Tissues. Vol 4. Lyon, France: International Agency for Research on Cancer (IARC); 920(08) 110-123.

[7] Falini, B., et al. Cytoplasmic nucleophosmin in acute myelogenous leukemia with a normal karyotype. N Engl J Med (2005) 352, 254-266.

[8] Falini, B., et al. Acute mlyeloid leukemia with mutated nucleophosmin (NPM1): is it a distinct entity? Blood (2011) $117,1109-1120$.

[9] Boissel, N., et al. Prevalence, clinical profile, and prognosis of NPM mutations in AML with normal karyotype. Blood (2005) 106, 3618-3620.

[10] Bennett JM, Catovsky D, Daniel M-T, et al. Criteria for the diagnosis of acute leukemia of megakaryocytic lineage (M7): a report ofthe French-American-British cooperative group. Ann Intern Med 1985; 103:460-2.

[11] Al-Husseinawi EK. A surrogate marker to detect nucleophosnim (NPM1) gene mutations in the cytoplasm of acute myeloid leukemia (AML) blast cells in 30 adult Iraqi patients. Annals of Saudi medicine. 2013 Nov 1; 33 (6):539.
[12] Dhahir EK, Dhahi MA. High frequency of nucleophosmin mutations in thirty two Iraqi adult patients with acute myeloid leukemia. International Journal of Applied. 2012 May; 2 (5).

[13] Al-Husseinawi EK. Molecular Detection of Type A Nucleophosmin Mutation for the First Time in Forty Four Iraqi Patients with AML: Correlation with prognosis. International Journal of Applied. 2013 Mar; 3 (3).

[14] Pazhakh V, Zaker F, Alimoghaddam K, Atashrazm F. Detection of nucleophosmin and FMS-like tyrosine kinase-3 gene mutations in acute myeloid leukemia. Annals of Saudi medicine. 2011 Jan; 31 (1):45.

[15] Rau R, Brown P. Nucleophosmin (NPM1) mutations in adult and childhood acute myeloid leukaemia: towards definition of a new leukaemia entity. Hematological oncology. 2009 Dec 1; 27 (4):171-81.

[16] Thiede C, Creutzig E, Illmer T, Schaich M, Heise V, Ehninger G, Landt O. Rapid and sensitive typing of NPM1 mutations using LNA-mediated PCR clamping. Leukemia. 2006 Oct 1; 20 (10):1897-9.

[17] Falini B, Martelli MP, Pileri SA, Mecucci C. Molecular and alternative methods for diagnosis of acute myeloid leukemia with mutated NPM1: flexibility may help. Haematologica. 2010 Apr 1; 95 (4):529-34.

[18] Kassem N, Hamid AA, Attia T, Baathallah S, Mahmoud S, Moemen E, Safwat E, Khalaf M, Shaker O. Novel mutations of the nucleophosmin (NPM-1) gene in Egyptian patients with acute myeloid leukemia: A pilot study. Journal of the Egyptian National Cancer Institute. 2011 Jun 30; 23 (2):73-8.

[19] Nafea D, Rahman MA, Boris D, Perot C, Laporte JP, Isnard F, Coppo P, Gorin NC. Incidence and prognostic value of NPM1 and FLT3 gene mutations in AML with normal karyotype. Open Hematology Journal. 2011; 5:14-20.

[20] Verhaak RG, Goudswaard CS, van Putten W, Bijl MA, Sanders MA, Hugens W, Uitterlinden AG, Erpelinck CA, Delwel R, Löwenberg B, Valk PJ. Mutations in nucleophosmin (NPM1) in acute myeloid leukemia (AML): association with other gene abnormalities and previously established gene expression signatures and their favorable prognostic significance. Blood. 2005 Dec 1; 106 (12):374754.

[21] Döhner K, Schlenk RF, Habdank M, Scholl C, Rücker FG, Corbacioglu A, Bullinger L, Fröhling S, Döhner H. Mutant nucleophosmin (NPM1) predicts favorable prognosis in younger adults with acute myeloid leukemia and normal cytogenetics: interaction with other gene mutations. Blood. 2005 Dec 1; 106 (12):3740-6.

[22] Wang L, Xu WL, Meng HT, Qian WB, Mai WY, Tong HY, Mao LP, Tong Y, Qian JJ, Lou YJ, Chen ZM. FLT3 and NPM1 mutations in Chinese patients with acute myeloid leukemia and normal cytogenetics. Journal of Zhejiang University Science B. 2010 Oct 1; 11 (10):762-70.

[23] Chen W, Rassidakis GZ, Medeiros LJ. Nucleophosmin gene mutations in acute myeloid leukemia. Archives of pathology \& laboratory medicine. 2006 Nov; 130 (11):1687-92. 